\title{
Development of digital educational environment in higher education
}

\author{
Natalia Arsenieva*, Ludmila Putyatina, and Lidia Uglova \\ Moscow Aviation Institute (National Research University), Moscow, Russia
}

\begin{abstract}
The article discusses the actual problem of improving the system of distance learning in higher schools as an important area of training of specialists taking into account time and long-term challenges of the development of the country's economy. It analyzes in detail all the advantages and disadvantages of modern digitalization of the educational process for training and retraining of specialists of a new formation for all areas of the economy of the Russian Federation and beyond. There are two main approaches to the digital economy: the classic approach, based on digital technologies, and the extended approach, which means economical production using digital technologies. The article gives modern concepts of "distance education", "distance learning", "online training", "e-learning" and others that are often used as synonyms. It reflects features of the educational process based on the wide use of interactive and problematic teaching methods that allow students and specialists of different levels to acquire the skill of analysis of the used arrays of digital information for making effective management decisions. It considers various types of resources that used to improve the quality of educational processes: educational, personnel, functional and technical, the basic requirements for them in modern education are given as well. It describes measures to expand and deepen the use of the digital economy in education and other areas of professional activity.
\end{abstract}

\section{Introduction}

According to the strategy of comprehensive implementation of Digital economy until 2030, it should be noted that digitalization consistently enters all spheres of business activity and becomes an indispensable part of the media landscape, taking into account the demands of both particular citizens and production for the spread of information technologies and telecommunications [4].

At the same time, this area allows to cooperate and coordinate the interests of all countries of the Eurasian Economic Union and other communities.

In conditions of transformation of the studies processes, the digital economy is widely and consistently implemented by all interested parties and combines relevant research and projects.

\footnotetext{
* Corresponding author: natars2002@yandex.ru
} 
For example, in the Russian Federation, business incubators that combine all areas of development and promotion of the digital economy were formed. However, Russia has yet to work out and implement certain standards for the content and storage of large arrays of digital information [1].

In order to successfully implement the strategy of introduction digital economy by 2024 , Russia plans to achieve the following milestones in the area of "Personnel and education": - annually train and graduate in educational institutions approximately 120,000 specialists in the field of information technologies;

- approximately 800,000 people in this field should comply with global standards;

- approximately $40 \%$ of the population of the country should be motivated to learn digitalization $[3,5,6]$.

\section{Materials and methods}

The main advantages of modern means of the digital economy, which consists in the significant simplification of all digital data for their high-speed transmission and use, should be noted.

For the implementation of educational processes online, various types of resources that should comply with the profile of training and curricula should be used. The main resources are:

Educational resources that include $[8,10]$ :

- Course programs that reflect the main sections and their detailed content;

- Lecture material (code) that corresponds to the program and that covers in detail particular topics and their value to the course in general;

- Practical tasks that allow to consolidate theoretical material on specific examples;

- Methodologies and methods of conducting classes that provide a direct connection with the audience and that allow to define the level of digestion of the material and bottlenecks of the course that require additional explanations with examples;

- Types and practices of solitary work that can be implemented on the basis of individual tasks, situations, development of specific management decisions, or reports. It is necessary to prepare the planned topic of reports in the framework of the course. Each report should be presented by the author that later answers the questions of the audience.

- Interactive methods of education, which are a way of mutual exchange of information, which also contributes to learning in the form of joint activities and business cooperation.

Educational theoretical materials should be provided to the audience in advance and, in order to increase the efficiency of educational communication, they should be reviewed by the audience to prepare questions for the professor in the course of the lessons [2].

Human resources that include:

- Professors that should comply with the following requirements: competence, ability to develop high-quality teaching materials, relevant response to questions coming from the audience, consistency, and goodwill;

- Programmers that are capable to use advanced computer programs and make changes to training materials in real time;

- Methodologists that control all educational materials for compliance of courses with the educational programs;

- Network consultants that serve the existing platforms of the educational process;

- Information system maintenance engineers who monitor their readiness and performance during the educational process.

Functional resources that include [7]:

- System of distance learning, which is based on the platform accepted in this institution of higher education; 
- Forums that are supposed to have a detailed discussion of the most problematic aspects of the course taking into account the preparedness of the audience and personal opinions of some listeners;

- Statistical databases that can accompany certain explanations or decryptions of the obtained theoretical information;

- Interactive websites that serve for demonstration of certain aspects of the considered theoretical material of the lectures;

- Tests (initial, intermediate, and final). Initial tests are used to assess the level of preparedness of the listeners for the course; intermediate tests reflect the average level of digestion of the certain material; final tests give an idea of the quality of the complete digestion of this course by the listeners;

- Problematic questions used in lectures and practical classes, reflecting the level of awareness of listeners on certain issues and the level of consistency of substantiation of answers;

- Electronic journals that are most often used to check the course attendance and mark the special abilities of certain listeners.

Technical resources are an important part of the educational process and are constantly in working condition. They include: computers, printers, scanners, projectors, web cameras, special boards, Internet access [9].

Since the main goal of all types of distance learning is to improve the quality of the educational process that is aimed at increasing the level of digestion of the educational material, improving professional competencies, there is a problem of the quality of management of the educational process that should strive for the greatest satisfaction of listeners [11].

The level of demand for various forms of the educational process is a reasonable indicator of its effectiveness.

In order to stimulate the effectiveness of education, it is necessary to:

- Study and offer to the students various methods of motivation of cognitive activity: the possibility of professional growth; getting into the personnel reserve of a certain organization; participation in various professional competitions and round tables, professional discussions; participation in professional testings of prestigious organizations.

- Extensive use of interactive methods of education and problem solving.

Social integration involves various types of information exchange in the process of mutual communication, i.e. a relaxed exchange of opinions and judgments on pre-formulated issues [12].

In the educational process in pedagogical practice, interactive methods and techniques as a mutual exchange of information that contributes to cognition in the form of joint activities and business cooperation are often used as well. This process contributes to the ability to conduct a dialogue in partnership and imitates the methodological aspects of making certain managerial decisions with the purpose of increasing the objectivity of their adoption.

\section{Results}

Based on the conducted analysis and taking into account the modern problems of the widespread of the digital economy in education, the country has a list of tasks for their effective solution:

- The use of a comprehensive approach to the creation and development of the educational environment in the Russian Federation.

- The use of national platforms in the educational environment of the country. 
- Creation and development of teaching materials and algorithms of dynamic sequential adaptation of educational processes taking into account the individual characteristics of students.

- Ensuring secure access of any interested person to the source of knowledge, regardless of territorial affiliation and distance.

- The most effective use of the scientific and pedagogical potential of the country taking into account its constant development.

- The use of a consistent transition to the digitalization of educational services based on special technology.

- Consistent expansion of the contingent of students studying in Russian for other countries.

\section{Discussions}

Despite all the prospects of distance education, taking into account its obvious advantages, there is currently no single point of view in the pedagogical community on the scale and speed of its spread in universities.

All pedagogical society divided into three groups: one group adheres to the maximal and quite fast implementation of online learning in a wide range of disciplines; other experts believe that the optimal combination of full-time and distance learning is the most promising; the third group consists of opponents of distance learning, which almost excludes personal contact with the audience, which is an essential element of the educational process.

Moreover, an important part of the discussion in this area can be considered incomplete information about the impact of distance learning on the health of students and professors.

When analyzing the influence of this type of education on certain aspects of people's life, it is necessary to state the following observations:

- A sufficiently long-term contact with the working equipment can lead to physical and psychological disorders in the form of sleep disturbances and depression.

- Interaction with a screen during active mental activity leads to rapid fatigue and reduces the level of perception of educational material by students, which can also lead to brain fatigue.

- A bright screen causes problems with vision, the deterioration of which can create certain restrictions on the use of distance education.

- Sitting at the computer for hours also creates spinal problems and changes posture.

- Specialists also note problems with diseases of the respiratory systems due to the attraction of dust accumulation in the electrolyzed environment and a decrease in humidity, which affect the appearance of allergic reactions of the body.

Moreover, the use of distant types of education decreases the level of social communication skills in the student environment, which leads to unjustified conflicts and sometimes inappropriate behavior of students.

The set of problems of the widespread introduction of distance learning leads to the need for a comprehensive study of them and a competent approach to preserving the educational environment.

\section{Conclusion}

For the implementation of educational processes online, various types of resources that should comply with the profile of training and curricula should be used. The main resources are educational, personnel, functional and technical.

The labour market is developing towards the demand for specialists who are able to constantly master and apply in practice related specialties and creatively approach the assigned tasks. The high level of imformation flows that are necessary in the process of 
carrying out professional duties makes modern students and young professionals additionally participate in educational processes.

Distance learning gets more and more development in Russia and in many countries of the world. This form of education has a list of advantages, the main advantages are: accessibily, efficiency, variety of forms of education, saving time and money, development of communication skills, effectiveness of education etc.

The current disadvantages of distance learning can be considered: inaccessibility of educational programs developed by some universities in the education environment; lack of uniform criteria of assessment (price-quality) of educational programs; absense of uniform approaches to terminology and definitions; lack of qualified analysis and review of distance learning experience in the Russian Federation, as well as its regulatory framework etc.

In order to stimulate the effectiveness of learning, it is necessary to widely use methods of motivating cognitive activity, as well as interactive and problem-based learning.

Moreover, an important part of the development of this area of activity can be considered incomplete information about the impact of distance learning on the health of students and professors.

The set of problems of the widespread introduction of distance learning leads to the need for a comprehensive study of them and a competent approach to preserving and developing the educational environment in the future.

\section{References}

1. About the priority project "Digital school" (n.d). http://government.ru/projects/selection/693/30822/

2. M. Berg, S. Lidén, B. Arnetz Computer screen allergy - a Swedish problem? Retrieved from https://www.ncbi.nlm.nih.gov/pubmed/8321645

3. A.V. Golubinskaya, International Journal of Humanities and Natural Science, 1, 161 (2015)

4. Implementation of access to online courses on the principle of "one window" (n.d). http://neorusedu.ru/activity/realizatsiya-dostupa-k-onlayn-kursam-po-printsipuodnogo-okna

5. B. K. Koichubekov, M. A. Sorokina, K. E. Mkhitaryan, Int. j. of applied and fundamental research 4, 71 (2014)

6. F. Mocci, A. Serra, G.A. Corrias, J. Occup. Environ. Med. 58(4), 267 (2001)

7. Modern digital educational environment in the Russian Federation (n.d). http://neorusedu.ru/about

8. A. Razmakhin, Digital totalitarianism versus "common sense": what is the future? https://zen.yandex.ru/media/id/593685a8d7d0a62756e9cfe3/cifrovoi-totalitarizmprotiv-zdravogo-smysla-za-chem-buduscee-5a85dd2ba815f1cda564c0a8

9. Report of the Federal state statistics service "Russia in numbers".(n.d). https://www.gks.ru/free_doc/doc_2019/rusfig/rus19.pdf

10. A.V. Sidorenkov, Question of psychology 1, 41 (2003)

11. L.A. Vitvitskaya, O.V. Studenikina, OSU Bulletin. Orenburg 12(200), 9 (2016)

12. E.V. Yazovskikh, Modern Economy Success 1, 33 (2018) 